Journal of Animal and Veterinary Advances 10 (9): 1177-1183, 2011

ISSN: $1680-5593$

(C) Medwell Journals, 2011

\title{
Seroprevalence of Brucellosis in Camels in and Around Dire Dawa City, Eastern Ethiopia
}

\author{
${ }^{1}$ Omer Mohammed, ${ }^{1}$ Bekele Megersa, ${ }^{1}$ Rahmeto Abebe, ${ }^{1}$ Mesele Abera, \\ ${ }^{1}$ Alemayehu Regassa, ${ }^{2}$ Yunus Abdrehman and ${ }^{1}$ Solomon Mekuria \\ ${ }^{1}$ School of Veterinary Medicine, Hawassa University, P.O. Box 05, Hawassa, Ethiopia \\ ${ }^{2}$ DireDawa Regional Veterinary Laboratory Head
}

\begin{abstract}
A cross-sectional study was conducted from November 2009-April 2010 to estimate seroprevalence of Brucella infection in camels and to identify risk factors associated with brucellosis infection in camels (Camelus dromedaries) in Dire Dawa city administration. A total number of 573 camels in 88 herds were sampled during study period. Out of these, 264 were females while 309 were male camels. All serum samples were initially screened by the Rose Bengal Plate Test (RBPT) and confirmation were made using Compliment Fixation Test (CFT). Accordingly, 9 were seropositive out of the 11 RBPT reactors. The overall seroprevalence of Brucella antibodies in camels was $1.6 \%$. Seroprevalence analysis against associated risk factor showed no significant difference $(p>0.05)$ except reproductive disorder where abortion showed significant difference $(p<0.05)$. In addition, camels that co-exist with small ruminants showed slight statistical difference $(\mathrm{p}=0.05)$. During blood sample collection owners showed that as they have no awareness about zoonotic importance of the disease. The owner drink raw milk and all animal owners did not take care of retained fetal membrane and aborted fetuses. Camel brucellosis was found to be well spread in the study area and the management practices and the tradition of using animal products warrant serious endanger of the society to Brucella infection.
\end{abstract}

\section{Key words: Camelus dromedaries, brucellosis, seroprevalence, RBPT, CFT, DireDawa, Ethiopia}

\section{INTRODUCTION}

One humped camel (Camelus dromedarius) is an important livestock species in Ethiopia uniquely adapted to hot and arid environments. Ethiopia takes the 3rd place in Africa next to Somalia and Sudan in possessing over one million camels. In Ethiopia camels are kept in arid and semi arid lowlands of the Borana, Somali and Afar region (Teshome et al., 2003).

The camels were and still are valued as riding, baggage, draught animals, hair hides and as well as the best food providers in the arid areas. Recently, camels are one the national export commodity especially in eastern part of Ethiopia. However, a rampant disease that affects camels and inaccessible environment remain one of the major constraints to address and investigate camel's diseases as well as to generate the valuable information related to this animal (Tigani et al., 2005). Brucellosis is a disease caused by varies species of the genus Brucella which is the most widely spread zoonosis worldwide (Dawood, 2008).

The disease can affect almost all domestic species and cross transmission can occur between cattle, sheep, goat, camel and other species (Ghanem et al., 2009). These diseases have great impact on economic development by affecting foreign market, apart from direct losses (morbidity and mortality) and indirect losses such as due to the costs of treatment and ineffective control measures (Perry et al., 2001).

Brucellosis has considerable public health importance as owners (Abbas et al., 1987; Gameel et al., 1993) consume raw camel milk. The prevalence is higher in intensive camel production system where large herd size kept at close proximity in a farm. In extensive management system the prevalence is low (Abbas and Agab, 2002). Infected animals show clinical signs of abortion and stillbirth in female and orchitis and epididymitis in male animals and infertility in both cases (Radostits et al., 1994; Agab, 1997; Straten et al., 1997). In production system where livestock diversification under practice, the disease circulates in sheep, goats and cattle and further spreads to dromedaries (Andreani et al., 1982; Radwan et al., 1992).

Camels are not known to be primary host for any of Brucella organisms but they are susceptible to both B. abortus and B. melitensis (Musa and Shigidi, 2001). Teshome et al. (2003) has reported 5.7 and $4.2 \%$ seroprevalence of brucellosis in camels kept in 3 arid and

Corresponding Author: Solomon Mekuria, School of Veterinary Medicine, Hawassa University, P.O. Box 05, Hawassa, Ethiopia 
semi arid region of Ethiopia (Afar, Somali, Borana) using Rose Bengal Plate Test (RBPT) and Complement Fixation Test (CFT), respectively.

Inline with favorable environment on agricultural entrepreneurship in Ethiopia there is camel export market in eastern part of the country Ethiopia. However, one of the key criteria to export camels is animals have to be free from brucellosis due to public health importance for importing countries. As the result of brucella test positive, a number of camels rejected from export market. Therefore, this study was designed with the objectives to estimate seroprevalance of camel brucellosis in Dire Dawa city administration and investigate associated risk factors for the occurrence of brucellosis.

\section{MATERIALS AND METHODS}

Study area: Dire Dawa city administration is a city located in the eastern part of Ethiopia within the valley surrounded by eastern mountain of Eastern Hararghe and at the verge of the semi-desert of Somali region. The city is located $505 \mathrm{~km}$ far from Addis Ababa to Eastern direction and $55 \mathrm{~km}$ to the North of historical city of Harare and $311 \mathrm{~km}$ to the west of port of Djibouti. The city has hot climatic condition with an average annual rainfall of $676.3 \mathrm{~mm}$ and the annual minimum and maximum air temperature is 18.2 and $34^{\circ} \mathrm{C}$, respectively. Majority of the livestock population owned by the rural peoples in and around the city are 43124 heads of cattle's, 185996 head of sheep and goats, 6438 heads of equine, 7260 head of camel and 34199 head of poultry.

Study animals: Camels (Camellus dromedarous) of one humped species were used for this study. Serum sample was collected for serological examination from selected camels; information of each camel sampled was recorded including its location, herd size, sex, age, physiological status, reproductive history, co-existence with other ruminants and history of parity.

Study design: A cross sectional study type was undertaken from November 2009-April 2010 to estimate the seroprevalance of camel brucellosis and associated risk factors in Dire Dawa city administration.

Sample size: The sample size of the study animals were determined by using the formula given for simple random sampling methods:

Where:

$$
\mathrm{n}=1.96^{2}\left[\mathrm{p}_{\exp }\left(1-\mathrm{p}_{\exp }\right)\right] / \mathrm{d}^{2}
$$

$\mathrm{n} \quad=$ Required sample size

$\mathrm{P}_{\exp } \quad=$ Expected prevalence of trypanosomosis $(50 \%)$ $\mathrm{d}=$ Desired absolute precision level at $95 \%$ confidence level (5\%)

$1.96=$ The value of $Z$ at $95 \%$ confidence level

Total sample size were 384 however, sample size were increased into 573 camels and randomly sampled from study area to widen the chance of observation and estimate the wide distribution of brucellosis in the study area.

Sampling strategy: Information on camel population in twenty seven-peasant association of Dire Dawa town administration was identified. Accordingly, total sample sizes were allocated proportionally for each PA's. Then the allocated sample size in each peasant association was randomly selected until the allocated sample size attained. Both sex and age above 2 years old considered for sampling.

Blood sample collection: Blood samples were collected aseptically from the jugular vein of the study animals during fieldwork by using plain vaccutainer test tube and then it brought to laboratory in an icebox. After the blood sample brought to laboratory it kept overnight to clot at slant position at room temperature. Then the separated serum was carefully collected in cryovial without mixing with the clotted blood. The serum was stored at $-20^{\circ} \mathrm{C}$ until further processing took place.

Serological examination: Rose Bengal Plate Test (RBPT) initially screened all samples for the presence of brucella agglutinin. Positive sera were then subjected to Complement Fixation Test (CFT) for further confirmation both tests were performed at Dire Dawa regional veterinary laboratory.

Laboratory procedure for RBPT: The Serra were kept at $+4^{\circ} \mathrm{C}$ for about $12 \mathrm{~h}, 75-90 \mathrm{~mL}$ of test sera were placed on glass slide. About 25-30 mL of RBPT antigen were added on the glass slide next to Serra. The antigen and test serum were mixed thoroughly by plastic applicator and shaked for 3-4 min. The result was graded as negative or positive based on the agglutination.

Interpretation: Showing no agglutination was recorded as negative while those with agglutination were recorded as positive.

Compliment fixation test: First, a known antigen was incubated with test and control serra to allow the formation of immune complexes. A well-defined amount of compliment was added to the reaction mixture. Only in 
positive reaction that specific antibodies and antigen create immune complexes and the compliment will be consumed.

In negative case there was no immune complexes formation and hence no consumption of compliment. All these reaction were visible and differentiation between positive and negative reaction was not possible up to this point. In the second reaction step, red blood cells and their specific antibodies were added and form complexes. In the positive case, no compliment was left over to hemolyze RBC. In the negative case, the compliment added in the 1 st reaction step was not consumed therefore it causes visible hemolytic after addition of the hemolytic system.

Interpretation: Serra with strong reaction $>75 \%$ fixation of the compliment (3+) at a dilution of 1:5 and at least with $50 \%$ fixation of compliment $(2+)$ at a dilution of $1: 10$ and at a dilution of 1:20 were classified as positive.

Data management and analysis: The data collected from field and serological test result were entered into Microsoft Excel spreadsheet and descriptive statistics were summarized. The relationship of associated risk factor with positive serological test result was analyzed by logistic regression using Stata software (version 9). A test value considered as statistically significant when $\mathrm{p}<0.05$.

\section{RESULTS}

Overall serological prevalence: In this study, 573 camels were screened from 88 camel herds. RBPT identified 11 seropositive reactors out of 573 serum samples $(1.9 \%)$. The positive reactors with RBPT were further confirmed using CFT. Accordingly, nine (1.6\%) seropositive camels were observed.

Seroprevalence in relationship to assumed risk factors Sex: All breeding male and female camels above 2 years of age were considered in the analysis. From the total camels tested $46.1 \%(\mathrm{n}=264)$ were females while $53.9 \%(n=309)$ were male camels. Seroprevalence of brucella in female animals were $1.9 \%$, relatively higher than that of the male camels $1.3 \%$ but there was no a significant difference $(p>0.05)$ observed in the analysis (Table 1).

Age: Age was one of the factors observed in the study. Categorization was based on the physiological maturity for breeding purposes where young group were considered below 4 years and adult group was 4 and above 4 years old. Out of the total camels, sampled $20.8 \%$ were young while $79.2 \%$ were adult camels. In this
Table 1: Seroprevalence brucella in relation to sex of the camels No. of No. of Percentage camels positive with $95 \%$

\begin{tabular}{llllll} 
Sex & tested & camels & \multicolumn{1}{c}{ CI } & \multicolumn{1}{c}{ OR } & p-value \\
Male & 309 & 4 & $1.3(0-2.6)$ & 1 & - \\
Female & 264 & 5 & $1.9(0.25-3.6)$ & $1.5(0.39,5.5)$ & 0.57 \\
Total & 573 & 9 & $1.6(0.6-2.6)$ & - & - \\
\hline
\end{tabular}

Table 2: Seroprevalence of brucella in relation to age group of camels sampled

No. of No. of camels positive Percentage

Age tested camels with 95\% CI OR

\begin{tabular}{llllll}
\hline Young & 119 & 2 & $1.7(0-4)$ & 1 & - \\
Adult & 454 & 7 & $1.5(0.4-2.6)$ & $0.92(0.19,4.5)$ & 0.91 \\
Total & 573 & 9 & $1.6(0.6-2.6)$ & & \\
\hline
\end{tabular}

Table 3: Seroprevalence of brucella in relation to herd size No. of No. of camels positive Percentage

Herd size tested camels $(95 \% \mathrm{CI})$

$\begin{array}{llll}\text { Small } & 216 & 5 & 2.3(0.3-4.3)\end{array}$

Medium $\quad 145 \quad 1$

Large

Total

observation seroprevalence of brucella was 1.7 and $1.5 \%$ in young and adult camels as shown in Table 2 . There was no statistical significance between 2 age groups $(\mathrm{p}>0.05)$.

Herd size: Herds size from which individual camels selected were categorized into 3 categories: small herd size were the group of animals in which the herd size ranges from 1-9, medium herd size ranges from 10-19 and large herd size considered when number of camels in the group ranges above 20 heads of camel.

Seroprevalence of brucella in relation to herd sizes were $2.3,0.7$ and $1.4 \%$ in small, medium and large herds, respectively (Table 3 ). Small and large herd size showed relatively high seroprevalence but werenot different significantly $(\mathrm{p}>0.05)$.

Camels with other ruminants: Other ruminants kept together with the camel herd were considered as one of the putative factor for dissemination of infection. This was categorized based on the absence and presence of other ruminant (small ruminant and/or cattle) together with the camel herds.

Of the total camels sampled $84.5 \%$ were kept without other ruminant whereas $12.2 \%$ were kept with small ruminant and $3.3 \%$ were with cattle. Accordingly, Seroprevalence was $1.03 \%$ in the absence of other ruminant, $4.3 \%$ in the presence of small ruminant and 5.3\% in the presence of cattle was seen (Table 4). There was significant difference $(\mathrm{p}<0.05)$ between camels herds with and in the absence of other animals where camel with small ruminants showed high seroprevalence (5.3\%). 
Table 4: Seroprevalence of brucella in relation to interaction of camels with other ruminant

\begin{tabular}{lrcllll}
\hline $\begin{array}{l}\text { Camel with } \\
\text { other flocks }\end{array}$ & $\begin{array}{c}\text { No. } \\
\text { tested }\end{array}$ & $\begin{array}{c}\text { No. of } \\
\text { positive } \\
\text { camels }\end{array}$ & $\begin{array}{c}\text { Percentage } \\
(5 \% \text { CI })\end{array}$ & OR & p-value \\
\hline Absence & 484 & 5 & $1.0(0.1-1.9)$ & 1 & - \\
Small ruminant & 70 & 3 & $4.3(0-9.1)$ & $4.3(1.0,18.4)$ & 0.05 \\
Cattle & 19 & 1 & $5.3(4.8-15.4)$ & $5.3(0.6,47.9)$ & 0.14 \\
Total & 573 & 9 & $1.6(0.6-2.6)$ & - & - \\
\hline
\end{tabular}

Table 5: Relationship between numbers of herd category with seroprevalence of brucella

\begin{tabular}{|c|c|c|c|c|c|}
\hline $\begin{array}{l}\text { Herd } \\
\text { category }\end{array}$ & $\begin{array}{l}\text { No. of } \\
\text { herds } \\
\text { tested }\end{array}$ & $\begin{array}{l}\text { No. of } \\
\text { positive } \\
\text { camels }\end{array}$ & $\begin{array}{l}\text { Percentage } \\
(95 \% \mathrm{CI})\end{array}$ & OR & $\mathrm{p}$-value \\
\hline Small & 60 & 5 & $8.33(1.3-15.3)$ & 1 & - \\
\hline Medium & 15 & 1 & $6.67(0-19.4)$ & $0.5(0.05,4.7)$ & 0.53 \\
\hline Large & 13 & 3 & $23.1(0-46.0)$ & $1.7(0.4,7.0)$ & 0.50 \\
\hline Total & 88 & 9 & $10.23(3.9-16.6)$ & - & - \\
\hline
\end{tabular}

Herd level analysis: The analysis was also seen from the herd level perspective in order to estimate seroprevalence of brucella in relation to number of each herd size. The overall seroprevalence within 88 herd was $10.23 \%$ (3.9-16.6). Seroprevalence in small, medium and larger herd level was 8.33\% (1.3-15.3), 6.67\% (0-19.4) and 23.08\% (0-46.0), respectively. However, there was no significant difference statistically ( $\mathrm{p}>0.05$ ) among herd size as shown in Table 5 .

Reproductive performance in relation to the infection Number of calving history in adult female camels (parity status): Number of calving by the adult female camels was one of the parameter considered during study period. Camels above 4 years of age were considered as adult female camel. The number of parity was used to categorize adult female. Accordingly, 9 calved (camels with no calving history), single parity (camel with single calving history) and multiparty (camels that calved two or more times) were the 3 categories used.

Among the adult females tested nearly $32.5 \%$ were none calved, $12.8 \%$ had single parity while $54.7 \%$ had two or more parity. Seroprevalence of brucella in single parity was $7.7 \%$ (2.6-18) and multiparty showed $0.9 \%(0-2.7)$. In this observation frequency of calving was not shown statistically significant different $(\mathrm{p}>0.05)$ (Table 6).

Reproductive disorder history of adult females: Reproductive disorder histories of the adult females were observed in relation to seroprevalence of brucella. Among these, a proportion of $95.1 \%$ camels with no history of reproductive disorder, $2.5 \%$ camels with abortion, $0.5 \%$ with stillbirth and $2 \%$ with retained fetal membrane history were observed. The observation shows that seroprevalence of brucella within a group of camels with history of no reproductive disorder was $0.52 \%(0.5-1.3)$ and with history of abortion was $40 \%$ (3-83).
Table 6: Frequency of calving of the adult female camels in relation to seroprevalence of brucella

\begin{tabular}{lrclll}
\hline Parturition & $\begin{array}{l}\text { No. of } \\
\text { tested }\end{array}$ & $\begin{array}{l}\text { No. of } \\
\text { positive }\end{array}$ & $\begin{array}{l}\text { Percentage } \\
(95 \% \mathrm{CI})\end{array}$ & OR & p-value \\
\hline No parturition & 66 & 0 & 0 & - & - \\
Single parity & 26 & 2 & $7.7(0-18)$ & 1 & - \\
More than one & 111 & 1 & $0.9(0-2.7)$ & 0.11 & 0.075 \\
Total & 203 & 3 & $1.5(0.2-3.2)$ & - & - \\
\hline
\end{tabular}

Table 7: Reproductive disorder in adult females in relation to brucella infection

\begin{tabular}{lllllll}
\hline $\begin{array}{l}\text { Reproductive } \\
\text { disorder }\end{array}$ & $\begin{array}{c}\text { No. of } \\
\text { examined }\end{array}$ & $\begin{array}{l}\text { No. of } \\
\text { cositive }\end{array}$ & $\begin{array}{c}\text { Percentage, } \\
(95 \% \mathrm{CI})\end{array}$ & OR & p-value \\
\hline $\begin{array}{l}\text { No disorder } \\
\text { Abortion }\end{array}$ & 193 & 1 & $0.5(0.5-1.3)$ & 1 & - \\
$\begin{array}{l}\text { Still birth } \\
\text { Retained }\end{array}$ & 1 & 2 & $40(3-83)$ & $128(8.9-1825)$ & $<0.001$ \\
fetal membrane & 4 & 0 & 0 & - & - \\
Total & 203 & 3 & 0 & & - & - \\
\hline
\end{tabular}

Seroprevalence between the two groups was significantly different $(\mathrm{p}<0.05)$. However, the sample size observed in a group of abortion was very small as compared to that of the group with no disorder history. Seroprevalence was not observed in other groups shown in Table 7 .

\section{DISCUSSION}

Zoonoses continue to represent an important health hazard in most parts of the world, particularly in developing countries (Stohr and Melsin, 1997). Brucellosis is a classical zoonosis and the major sources of infection remain contact with infected animals or the handling of carcasses. Less frequently it is acquired through food. Camels are not known to be primary hosts of Brucella organisms but they are susceptible to both $B$. abortus and B. melitensis (Cooper, 1991). The seroprevalence of brucellosis in camels appears to follow two distinct patterns: a low (2-5\%) prevalence in nomadic or extensively kept camels and a high (8-15\%) prevalence in camels kept intensively or semi-intensively (Abbas and Agab, 2002). In this study $1.6 \%$ over all seroprevalence of brucella was observed which has in agreement with the $1.2 \%$ seroprevalence in Borena zone of southern Ethiopia by Teshome et al. (2003); $1.7 \%$ in Tigray and $1.7 \%$ in Hararghe regions of Ethiopia by Domenech. As most of camels are kept by nomadic people despite the variation in region or locality where all area practice extensive farming system which agrees with the report of Abbas and Agab (2002) that seroprevalence was low in this study.

Other serological surveys which shows in accordance with this records includes $1.9 \%$ prevalence in Somalia by Baumann and Zessin (1992); 1.4\% prevalence in Saudi Arabia by Hashim et al. (1987) and 1.93\% in that 
of Iran. In contrast to present study there was relatively high seroprevalence $(5.2 \%)$ in Afar and $2.8 \%$ in Somali regions of Ethiopia by Teshome et al. (2003). Brucellosis in camel have been reported in many countries showing different seroprevalence: Saudi Arabia, 4.3-8.6\% (Radwan et al., 1992); Egypt, 10-20\% (Radwan et al., 1992); Sudan, 4.9\% (Abu Damir et al., 1984) and Somalia, $3.1 \%$ (Ghanem et al., 2009). These varying reactor rates for camel brucellosis in different countries may be due to varying husbandry and management practice, susceptibility of the animal, virulence of the organisms, presence of the reactor animals in the region, absence of veterinary service, lack of awareness by the nomads about the diseases and the pastoralists' movement from place to place.

The movement of animals may worsen the epizootic situation of brucellosis in an area as the movement contributes on disease spread from one herd to another due to the movement of an infected camel into a susceptible camel herd (Radostits et al., 1994). Seroprevalence of brucellosis in relation to sex of animals as some of the researchers reported significantly higher prevalence in females than in males (Hussein et al., 2005) while others in Sudan (Abu Damir et al., 1984) and Saudi Arabian (Radwan et al., 1992) reported that male camels have high antibodies against brucella infection more frequently than females. This study shows a slight difference in seroprevalence of brucella in female $(1.9 \%)$ than male camels $(1.3 \%)$ which have in agreement with the former findings.

Relatively higher susceptibility of females could be because females have more physiologically stressed than males (Walker, 1999). Infection may occur in animals of all age groups but persists commonly in sexually mature animals (Radostits et al., 1994). Younger animals tend to be more resistant to infection and frequently clear infections although few latent infections may occur (Radostits et al., 1994; Walker, 1999). In this study there was no significant difference between young (2-4 years) and adult (above 4 years age) age groups. This might be associated with management system where both age groups were kept together for grazing as well as for watering. The young group in this study were those age group between 2-4 years has already wined there maternal immunity and are equally susceptible like adult groups. Those age groups below the age 2 years even though they are kept together with the herd, they are known to be less susceptibility because of maternal immunity. Susceptibility appears to be more commonly associated with sexual maturity and risk of infection increases with pregnancy as the stage of pregnancy increases (Crawford et al., 1990).
Seroprevalence in camel kept without other ruminants with small ruminants and with large ruminants were 1.03 , 4.3 and $5.3 \%$, respectively. There was no significant difference observed between camel group with small ruminant and large ruminant but there was slight statistical significant difference observed as compared to group of camels with small ruminant and without ruminant $(\mathrm{p}=0.05)$. Andreani et al. (1982) reported significant different in Somalia where high chance of brucella transmission from ruminants to camels as they live in free range proximity in the bush and watering points.

Ismaily et al. (1988) of Oman and Radwan et al. (1992) of Saudi Arabia have recorded that contact between camels and small ruminants were more incriminated for the transmission of brucellosis to the camels. In addition, Abou-Eisha (2000) observed high seroprevalence in camels with the history of sheep and goats kept together.

Camel pastoralists in variability keep relatively large flock of sheep and goat alongside the camels (Abbas and Tilly, 1991). A contributing factor to the spread of the disease may be the movement of animals for grazing and watering during the dry season as aggregating the animals around watering point will increase the contact between infected and healthy animals and thereby facilitate the spread of the disease (Richard, 1979). Besides this, no hygienic measures are adopted during milking and allowing calves to suckle both before and after milking. This indicates that it is not only the milkers that transmit the disease from one camel to another but also the calves became infected. Absence of restrict control of animal movement at the border of Ethiopia and the neighboring countries which also facilitate the spread of the infection (Teshome et al., 2003). Brucellosis in camels causes abortion, placental retention, fetal death and mummification, delayed sexual maturity and infertility (Musa and Shigidi, 2001). In this study the seroprevalence in aborted female camels was $40 \%$ which has in agreement with the idea of Musa and Shigidi (2001) where they observed seroprevalence ranging from $3.1-72.7 \%$ in camels with reproductive disorders in different regions of Sudan. In this study camels with reproductive disorder were few in number and this might be the reason for zero seroprevalence, especially in those groups of camels with retained fetal membrane and stillbirth.

\section{CONCLUSION}

The present study provides the status of camel brucellosis in the Dire Dawa city administration and the risk factors that contribute to the occurrence of the disease in dromedaries as well as possible zoonotic implications in human beings. The seroprevalence was 
low which was similar to many research findings. Even though the number is small because of the nature of the disease it is excess to affect the health status and export market economy of the country as well as the public health at large. The sero-prevalence study showed that there is no statistically significant difference in the occurrence of brucellosis among different ages, sexes and herd size but showed statistically slight difference between groups co-exist with small ruminant and without other ruminant. Though the number of aborted camel sampled were small there was significant different as compared to apparently healthy group. It indicates that there is more risk of brucellosis infection in camels that co-exist with other ruminants and abortion might be one of the typical signs of brucellosis. Lack of awareness about brucellosis together with existing habit of raw milk consumption and close contact with animals can serve as means of infection to human beings.

\section{RECOMMENDATIONS}

- Camel pastoralists are often marginalized from public services, facilities and information. Thus awareness (public health education) on modern animal husbandry, disease prevention and risk of zoonotic diseases is quite necessary

- Further research that intended to the isolation of causative agent and identification of species and biotypes in Ethiopia is important

- Dromedaries thrive, produce and sustain life under number of constraints. Hence, research that features these animals and maximizing its performance is recommended

- Research should be conducted in order to produce and give effective vaccines against the strains of Brucella in camels in different pastoral community because they are the animals determining the lively hood of these communities by far better than test and slaughter

\section{REFERENCES}

Abbas, B. and H. Agab, 2002. A review of camel brucellosis. Prev. Vet. Med., 55: 47-56.

Abbas, B. and P. Tilly, 1991. Pastoral management for protecting ecological balance in Halaib District, Red Sea Province, Sudan. Nomadic Peoples, 29: 77-86.

Abbas, B., A.E. El-Zubeir and T.T. Yassin, 1987. Survey for certain zoonotic disease in camels in Sudan. Rev. Elev. Med. Vet. Pays. Trop., 40: 231-233.
Abou-Eisha, A.M., 2000. Brucellosis in camels and its relation to public health. Asuit Vet. Med. J., 44: 54-64.

Abu Damir, H., S.J. Kenyon, A.E.K. Alla and O.F. Idris, 1984. Brucella antibodies in Sudanese camels. Trop. Anim. Health Prod., 16: 209-212.

Agab, H., 1997. Clinical signs of animal brucellosis in eastern Sudan. Revue de Elevage et Medicine Veterinaire des Pays Tropicaux, 50: 97-98.

Andreani, E., S. Prosperi, A.H. Salim and A.M. Arush, 1982. Serological and bacteriological investigation on brucellosis in domestic ruminants of the somali democratic republic. Rev. Elev. Med. Vet. Pays. Trop., 35: $329-333$.

Baumann, M.P.O. and K.H. Zessin, 1992. Productivity and health of camels (Camelus dromedarius) in Somalia: Associations with trypanosomosis and brucellosis. Trop. Anim. Health Prod., 24: 145-156.

Cooper, C.W., 1991. The epidemiology of human brucellosis in a well defined urban population in Saudi Arabia. J. Trop. Med. Hyg., 94: 416-422.

Crawford, R.P., J.D. Huber and B.S. Adams, 1990. Epidemiology and Surveillance. In: Animal Brucellosis, Nielsen, K. and J.R. Duncan (Eds.). CRC Press, Florida, pp: 131-148.

Dawood, H.A., 2008. Brucellosis in camels (Camelus dromedorius) in the south province of Jordan. Am. J. Agric. Biol. Sci., 3: 623-626.

Gameel, S.E.A.M., S.O. Mohamed, A.A. Mustafa and S.M. Azwai, 1993. Prevalence of camel brucellosis in Libya. Trop. Anim. Health Prod., 25: 91-93.

Ghanem, Y.M., S.A. El-Khodery, A.A. Saad, A.H. Abdelkader, A. Heybe and Y.A. Musse, 2009. Seroprevalance of camel brucellosis (Camelis dromedarus) in Somaliland. Trop. Anim. Health Prod., 41: 1779-1786.

Hashim, N.H., G.A. Galil, M.A. Hulaibi and E.M. Al-Saleem, 1987. The incidence of brucellosis and species of Brucella organisms isolated from animals in Al Hasa, Saudi Arabia. World Anim. Rev., $61: 32-53$.

Hussein, A.A., A.S. Sayed and M.A. El-Feki, 2005. Seroepidemiological study on human brucellosis in Assiut Governorate. Egypt. J. Immumol., 12: 49-56.

Ismaily, S.I.N., H.A.M. Harby and P. Nicoletti, 1988. Prevalence of brucella antibodies in four animal species in the Sultanate of Oman. Trop. Anim. Health Prod., 20: 269-270.

Musa, M.T. and M.T.A. Shigidi, 2001. Brucellosis in camels in intensive animal breeding areas of Sudan: Implications in abortions and early-life infection. Revue Elev. Med. Vet. Pays. Trop., 54: 11-15.

Perry, B., J. McDermott and T. Randolph, 2001. Can epidemiology and economics make a meaningful contribution to national animal-disease control. Preventive Vet. Med., 48: 231-260. 
Radostits, O.M., D.C. Blood and C.C. Gay, 1994. Brucellosis Caused by B. abotus and $B$. melitensis. In: Veterinary Medicine: Textbook of the Diseases of Cattle, Sheep, Pigs, Goats and Horses, Radostits, O.M., D.C. Blood and C.C. Gay (Eds.). 8th Edn., B ailliere Tindall, London, pp: 787-792.

Radwan, A.I., S.I. Bekairi and P.V. Prasad, 1992. Serological and bacteriological study of breucellosis in camels in central Saudi Arabia. Rev. Sci. Tech., 11: $837-844$.

Richard, D., 1979. Study of the pathology of dromedary in Borona Awraja (Ethiopia). Doctor Thesis, Veterinaire Maisons-Alfort, IEMVT Institute.

Stohr, K. and F.X. Melsin, 1997. The role of veterinary public health in the prevention of zoonosis. Arch. Virol. Suppl., 13: 207-218.
Straten, M., Z. van Bercovich and Z.U. Rahaman, 1997. The diagnosis of brucellosis in female camels (Camelus dromedarius) using the milk ring test and milk ELISA: A pilot study. J. Camel Practice Res., 4: 165-168.

Teshome, H., B. Molla and M. Tibbo, 2003. A seroprevalence study of camel brucellosis in three camel-rearing regions of Ethiopia. Trop. Anim. Health Prod., 35: 381-390.

Tigani, T.A., A.B. Hassan and A.D. Abaker, 2005. Bacteriological and pathological studies on condemned lungs of one humped camels (Cameleus dromedarius) Slaughtered in Tamboul and Nyala abattoirs, Sudan. University of Nyala Faculty of Veterinary Science Department of Pathology, Nyala, Sudan.

Walker, R.L., 1999. Brucella. In: Veterinary Microbiology, Hirsh, D.C. and Y.C. Zee (Eds.). Blackwell Science Inc., London, pp: 196-203. 